\section{Does High Frequency Transcutaneous Electrical Nerve Stimulation (TENS) Affect EEG Gamma Band Activity?}

\author{
Ebrahimian M.1,2, Razeghi M.1,3, Zamani A.4, Bagheri Z.5, \\ Rastegar K. ${ }^{6}$, Motealleh A. ${ }^{1,3 *}$
}

\begin{abstract}
Background: Transcutaneous electrical nerve stimulation (TENS) is a noninvasive, inexpensive and safe analgesic technique used for relieving acute and chronic pain. However, despite all these advantages, there has been very little research into the therapeutic effects of TENS on brain activity. To the best of our knowledge, there is no evidence on the effect of high frequency TENS on the gamma band activity.
\end{abstract}

Objective: Investigation of the effect of high frequency TENS on the electroencephalographic (EEG) gamma band activity after inducing ischemic pain in healthy volunteers is considered.

Material and Methods: The modified version of Submaximal effort tourniquet test was carried out to induce tonic pain in 15 right-handed healthy volunteers. The high frequency TENS $(150 \mu$ s in duration, frequency of $100 \mathrm{~Hz})$ was applied for 20 minutes. Pain intensity was assessed at using Visual Analog Scale (VAS) in two conditions (after-pain, after-TENS). EEG gamma band activity was recorded by a 19-channel EEG in three conditions (baseline, after-pain and after- TENS). The repeated measure ANOVA and paired-sample T- tests were used for data analysis.

Results: EEG analysis showed an increase in gamma total power after inducing pain as compared to baseline and a decrease after the application of TENS (mean \pm SD: $.043 \pm .029$ to $.088 \pm .042$ to $.038 \pm .022 \mu \mathrm{V}^{2}$ ). The analysis of VAS values demonstrated that the intensity of induced pain (mean \pm SD: $51.53 \pm 9.86)$ decreased after the application of TENS (mean \pm SD: $18.66 \pm 10.28$ ). All these differences were statistically significant $(\mathrm{p}<.001)$.

Conclusion: The results of this study revealed that the high frequency TENS can reduce the enhanced gamma band activity after the induction of tonic pain in healthy volunteers. This finding might help as a functional brain biomarker which could be useful for pain treatment, specifically for EEG-based neurofeedback approaches.

\section{Keywords}

Transcutaneous Electric Nerve Stimulation (TENS), Gamma Rhythm, Oscillations, Pain Measurement, Tourniquet Pain Test, Electroencephalography (EEG)

\section{Introduction}

ranscutaneous electrical nerve stimulation (TENS) is defined as an application of electrical stimulation to the skin so as to control pain [1]. To alleviate pain perception, TENS employs a low voltage electrical current to the skin via surface electrodes. This stimulates afferent nerve fibers [2]. The International Association for the Study of
${ }^{1}$ Department of

Physi $\neg$ otherapy, School

of Rehabilitation Sci-

ences, Shiraz University

of Medical Sciences,

Shiraz, Iran

2Student Research

Committee, School of

Rehabilitation Sciences,

Shiraz University of

Medical Sciences, Shi-

raz, Iran

${ }^{3}$ Rehabilitation Sciences

Research Center, Shiraz

University of Medical Sci-

ences, Shiraz, Iran

${ }^{4}$ Department of Medical

Physics, School of Medi-

cine, Shiraz University

of Medicine Medicine,

Shiraz, Iran

${ }^{5}$ Department of Biosta-

tistics, School of Biosta-

tistics, Shiraz University

of Medical Sciences,

Shiraz, Iran

${ }^{6}$ Department of Physiol-

ogy, School of Medicine,

Shiraz University of

Medical Sciences, Shi-

raz, Iran

*Corresponding author:

A. Motealleh,

School of Rehabilitation

Sciences, Shiraz Univer-

sity of Medical Sciences,

Abiverdi 1 Ave., Chamran

Blvd, Shiraz, Fars, Iran

E-mail: motealleh@

sums.ac.ir

Received: 20 May 2017

Accepted: 14 January 2018 
Pain (IASP) works on two types of TENS: high frequency TENS [50-100 Hz, pulse per second (pps)], with low intensity (paresthesia, non-painful), pulse duration (50-200 $\mu$ s); and low frequency TENS ( $<10 \mathrm{pps})$, with high intensity (to tolerance threshold), pulse duration (100-400 $\mu \mathrm{s})$ [3]. What makes TENS worthwhile is that this technique, while substantially relieving acute and chronic pain, is noninvasive, inexpensive, safe and easy to use. It has been used for more than 45 years $[1,4,5]$. However, despite all these advantages, there has been very little research into the therapeutic effects of TENS on brain activity [6]. Furthermore, although there is ample evidence to suggest that TENS has immense therapeutic benefit, its extra-segmental mechanisms have not so far been studied widely $[7,8]$.

In the past, electroencephalogram (EEG) was used to evaluate the analgesic effects and extra-segmental mechanisms of TENS $[6,7$, 9-11]. But, although scholars have acknowledged low spatial resolution of EEG, it is shown to be a valuable tool because of having an excellent temporal resolution [12]. Theoretically speaking, EEG is very useful for its sensitivity to millisecond changes in cortical activities. This feature of EEG is even superior to both positron emission tomography (PET) and functional magnetic resonance imaging (fMRI), making it a useful tool for examining primary activity as soon as ascending signals reach the cerebral cortex and the information is sent to surrounding areas [13]. The EEG detects changes happening in the brain cortex areas concerned with receiving and processing nociperceptive inputs [7]. This makes EEG a valuable and practical tool to evaluate cortical pain modulation in clinical contexts [14].

In preceding studies, in order to investigate the impact of TENS on brain activities, scholars used a small number of electrodes (1-5 electrodes) for recording sensory [6, 7, 9-11] and motor $[9,16]$ cortex activities. Pain, as a submodality of somatic sensation has cognitive, affective and sensory characteristics
$[18,19]$. Hence, to assess pain thoroughly in a complex network in different regions of the brain, and to find the effects of TENS on pain relief; researchers should employ more electrodes, leading to a higher resolution and yielding more precise information about brain activities.

Furthermore, some previous studies investigated an extra-segmental mechanism of TENS in which noxious laser stimulation $[10,11]$ or short-term painful electrical stimulation [9] was used so as to induce pain, trigger a phasic pain. However, this stimulation is so short that they make it impossible to simulate clinical pain. To study pain, induced tonic pain is recommended to be used to stimulate clinical pain $[20,21]$. In the past, in order to assess the effects of TENS, most studies relied on the alterations made in the amplitude of sensory evoked potential, pain-related evoked potential, pain-related cortical magnetic fields [9, 11] or motor evoked potential [16, 22]. Among studies reviewed, just one surveyed the oscillation of brain waves and that study focused merely on EEG alpha band [6].

Findings of previous studies have shown that induced pain causes noticeable changes in all kinds of brain waves [23-27]. Hence, for a thorough investigation of the mechanism of TENS on pain relief, it seems necessary to study other brain waves [6], such as gamma band.

Gamma band is a kind of brain wave which consists of very rapid oscillations $(>30 \mathrm{~Hz})$. This rhythm suggests that the construction of a coherent concept, require the correlation among the input received from different cerebral areas. This reflects a mutual relationship between cortico-cortical and cortico-thalamocortical networks [28]. Moreover, it has been found that gamma band has an important role in pain perception as well as pain processing [29-34].

Regarding these findings, we hypothesized that high frequency TENS, as an analgesic modality, might change in the gamma band 
activity. Therefore, the aim of this study is to investigate the effect of high frequency TENS on the gamma band activity. To the best of our knowledge, this is the first study conducted to investigate the effects of high frequency TENS on the gamma band activity.

\section{Material and Methods}

\section{Participants}

Fifteen healthy right-handed volunteers (8 females, 7 males) participated in this interventional study. They were recruited after the related advertisements were placed on all university notice sections. The participants were included in this study if they were 18-25 years old, had never used TENS, had no history of relevant neurological or psychiatric diseases in the past or at present. In addition, they should not have taken medications affecting EEG recording [35], and with no peripheral vascular abnormalities, hypertension and hypotension or peripheral neuropathies [36]. Having screened out the volunteers, and in order to make them familiar with the aim of the study, they were asked to participate in certain meetings and were given some information about TENS and the ischemic pain induction procedure. All participants signed a written consent form and were informed that they could leave the experiment whenever they wished. Participants were asked not to consume caffeine 24 hours before the experimental session because it might hinder the effect of TENS [37] .

All experimental procedures were approved by the Ethics Committee (CT-9372-7272).

\section{Procedures \\ Pain Induction Method}

The submaximal-effort tourniquet test (SETT) has been used for the assessment of analgesic efficacy of drugs and electrotherapy in many studies [38-40]. The pain induced by SETT is deep, aching and constant in nature [41]. In terms of severity and duration, this pain resembles the clinical pain [42]. In the current study, the modified version of SETT was used. This has been employed in some other studies [3, 43-44].

Before undertaking the experiment, the maximal grip force was determined by means of a dynamometer $\left(\mathrm{SEAHAN}^{\circledR}\right.$, Masan, Korea). Then, $75 \%$ of the maximal grip force was calculated and identified on the dynamometer scale. The ischemic pain was induced as follows: the participants were instructed to raise their arm vertically above head for 1 minute to desanguinate the limb. A 10-cm sphygmomanometer cuff, which was applied $5 \mathrm{~cm}$ below the elbow crease, was inflated to $170 \mathrm{~mm} \mathrm{Hg}$ [45] at a rate of $40 \mathrm{mmHg}$ per second. After that, the arm was left in the horizontal position and was instructed to be placed on the side table. Subsequently, participants performed 15 hand gripping exercises $[21,46]$ at $75 \%$ maximal grip force for 1 minute (squeeze for $2 \mathrm{sec}$ and release in $2 \mathrm{sec}$ ). These exercises caused steadily increasing ischemic pain in the forearm [47]. Pain intensity was assessed 1 minute after the completion of the hand gripping exercises using a 0 to $100 \mathrm{~mm}$ Visual Analog Scale (VAS) anchored at no pain and worst imaginable pain. The SETT was performed on the non-dominant limb so that the participants could use the dominant one for making the pain level on VAS [3]. At the end of the experiment, the cuff was vigilantly deflated for 40 seconds to resanguinate the limb. It is worth mentioning that after inducing the ischemic pain, the participants experienced no trauma in their arms [3, 43].

\section{EEG Recording}

The EEG was recorded from $19 \mathrm{Ag} / \mathrm{AgCl}$ electrodes with an electrode cap (Neurowerk EEG-EMG system, Sigma, Germany), which were placed according to the 10-20 international system [48]. The referential electrodes were connected bilaterally to two earlobes. The cut-off frequencies of the EEG amplifiers were set to $0.5 \mathrm{~Hz}$ and $100 \mathrm{~Hz}$. A $50 \mathrm{~Hz}$ notch filter was set to minimize electrical interference [35]. EEG signals were digitized at the 
sampling rate of $256 \mathrm{HZ}$ at all channels ( Fp1, Fp2, F7, F3, Fz, F4, F8, T3, C3, Cz, C4, T4, T5, P3, Pz, P4, T6, O1, O2) [48]. The impedance of electrodes was monitored not to rise beyond $10 \mathrm{~K} \Omega[6]$.The recorded EEG data was analyzed off-line.

\section{TENS Intervention}

A dual-channel TENS unit (Multi Stim735, Novin ${ }^{\circledR}$, Iran) was used for pain relief. The stimuli were conveyed through two pairs of carbon rubber electrodes $\left(5 \times 5 \mathrm{~cm}^{2}\right)$ with pads. In order to generate electrical paresthesia around the cuff, electrodes were put along the midline of the ventral and dorsal sides of forearm (Figure 1). This position was reported to be effective in earlier SETT studies [3]. A biphasic asymmetric rectangular wave form with a pulse duration of $150 \mu \mathrm{s}$, frequency of $100 \mathrm{~Hz}$ and a continuous pulse pattern were used [3]. Previous studies recommended that the intensity of TENS should be titrated to gain the possible strongest intensity to achieve maximum pain relief [2]. Hence in this study, to induce strong but comfortable tingling sensation on the area under study, the current intensity was modified individually [11].

\section{Data Collection}

In the current study, the participants were in a half lying position to prevent the contraction of the muscles of head, face, neck and extremities. This will prevent muscle artifacts while recording EEG waves. In order to minimize the ambient noise interfering with EEG waves, the electrical and adjacent electronic circuits were turned off. To reduce the circadian effect on EEG waves, all participants were managed to test at the same time of the day (9-12 a.m.), and the room temperature was set between $\left(22-24^{\circ} \mathrm{C}\right)[35]$. The EEG were recorded while the subjects were relaxed, but wakeful and alert.

To perform the experiment, EEG electrodes were placed on the participant's heads in the order mentioned already. The EEG recording was performed for 2 minutes and considered as the baseline EEG. Then, as described above, by means of SETT, an ischemic pain was induced in the left forearm and hand. Afterwards, the participant marked his/her pain intensity on VAS. After-pain EEG was recorded for other 2 minutes. Later, the TENS current was applied for 20 minutes as described previously. Subsequently, the TENS unit was turned off and the participant marked his/ her pain and intensity. After-TENS EEG was recorded for other 2 minutes. Then, the cuff was deflated for 40 seconds to resanguinate

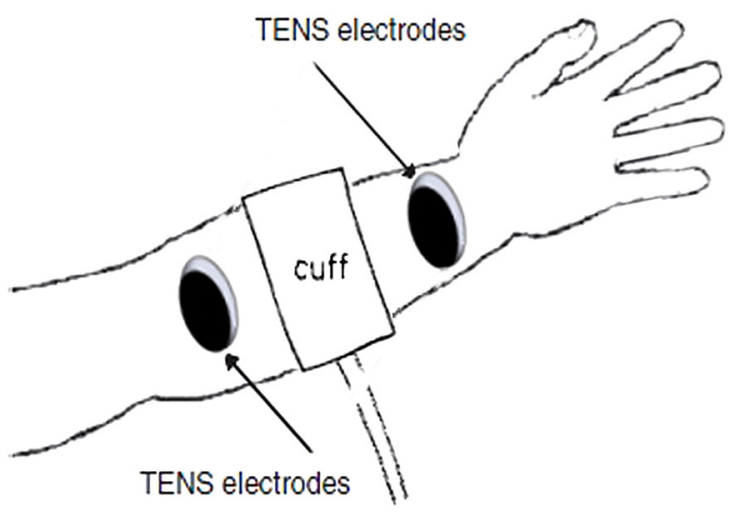

Figure 1: Position of transcutaneous electrical nerve stimulation (TENS) electrodes and sphygmomanometer cuff. 
the limb. The study protocol is summarized in Figure 2.

\section{EEG Processing}

EEG signals were analyzed offline via a custom written Matlab ${ }^{\circledR}$ Program, version R2014a (Mathworks Inc, Natick, MA, USA). First, the signals were evaluated by visual inspections. Then, if certain portions of the EEG record exhibited blink-related or muscle artifacts, they were removed via Matlab codes, and only artifact-free sections were subjected to analyze. The gamma band $(30-50 \mathrm{~Hz})$ total power $\left(\mu V^{2}\right)$ pooled from 19 channels were calculated at each recording condition (baseline, after- pain, after-TENS). This would indicate the EEG power at each recording condition precisely.

\section{Statistical Analysis}

The processed data were statistically analyzed using IBM $^{\circledR}$ SPSS, version 23.0 (IBM Corp, Armonk, NY, USA). To verify the normal distribution of the data (gamma band EEG power and VAS values), KolmogorovSmirnov test was used. The repeated measure ANOVA and paired-sample T- tests were employed to compare gamma total power (baseline, after-pain, after-TENS) and pre-post VAS values, respectively with a significance level of $95 \%(p<0.05)$.

\section{Results}

Fifteen healthy right-handed volunteers [( 8 females, 7 males), age: $21.13 \pm 0.38$ years old, weight: $67 \pm 15.92 \mathrm{~kg}$, height: $170.26 \pm 10.66$ $\mathrm{cm}$ ] participated in this interventional study.
The Kolmogorov-Smirnov test verified that the gamma total power and VAS values were normally distributed.

The EEG analysis showed an increase in gamma total power after inducing pain, as compared to baseline and a decrease after the application of TENS (.043 \pm .029 to $.088 \pm .042$ to $.038 \pm .022 \mu \mathrm{V}^{2}$ ); all these differences were statistically significant $[\mathrm{F}(2,28)=11.58$, $(\mathrm{p}<0.001)$ ] (Figure 3).

VAS values analysis demonstrated that the intensity of induced pain (mean $\pm \mathrm{SD}$ : $51.53 \pm 9.86)$ decreased after the application of TENS (mean \pm SD: $18.66 \pm 10.28$ ) and this decrease was also statistically significant $(\mathrm{p}<0.001)$.

\section{Discussion}

The current study aimed to investigate the effect of high-frequency TENS on gamma band activity following tonic pain induced in healthy volunteers.

\section{Alteration of Gamma Band Activity}

In this study, the EEG analysis revealed significant enhancement of gamma total power after inducing pain as compared to baseline. The observed increase in gamma total power after induced pain in current study, might be an indicator of the critical role of gamma wave in pain perception and processing.

This finding is in agreement with the results of preceding studies, indicating that the enhancement of gamma oscillations might be due to the cortical representation of tonic painful stimulus processing. Scholars suggested that the enhanced gamma oscillations could

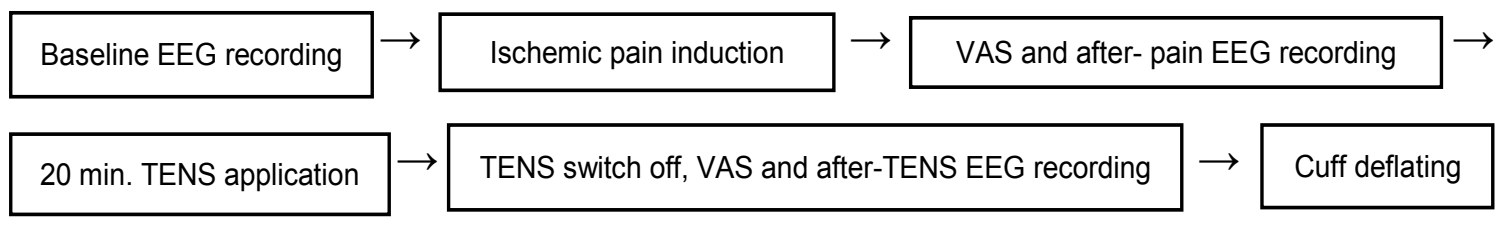

Figure 2: Study Protocol. 


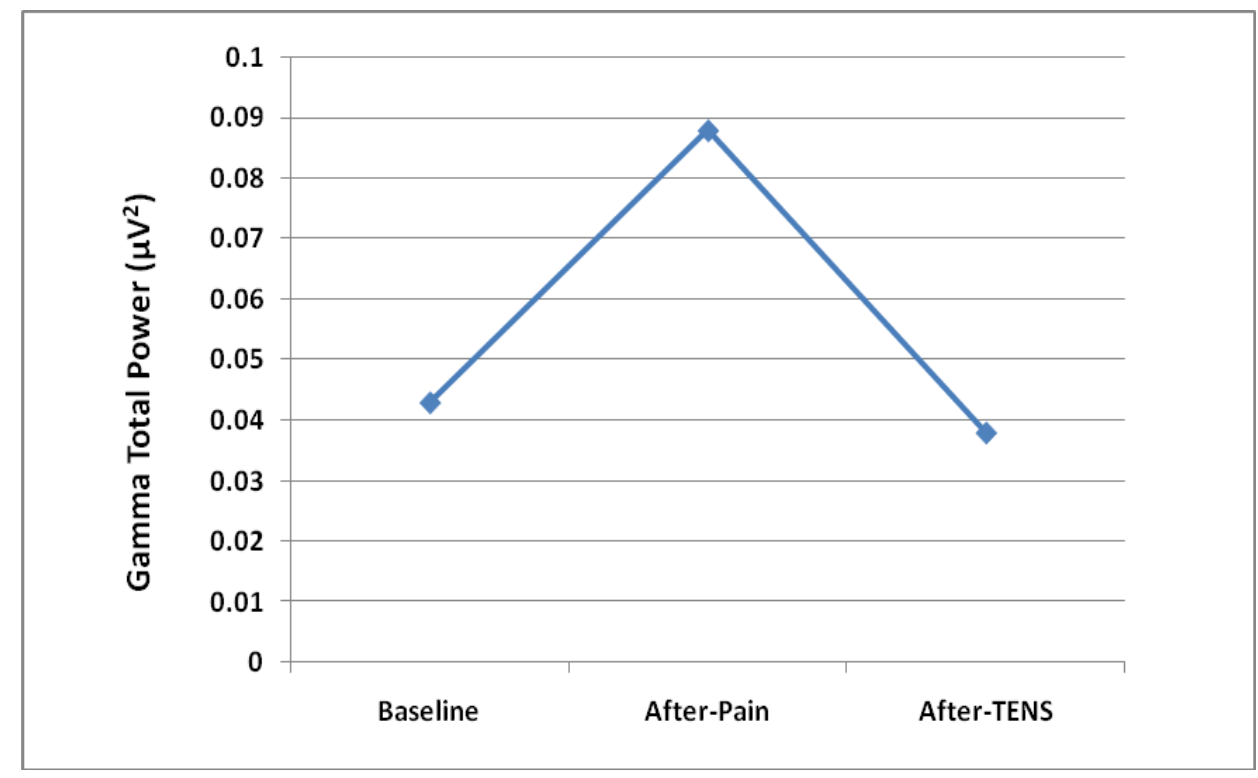

Figure 3: Significant repeated measure ANOVA between the sequential conditions (baseline, after-pain, after-TENS) on the gamma total power.

be interpreted as the bottom-up activation of cortical networks, yielding a subjective perception of pain [50-51]. It is noticed that the broadly distributed gamma oscillations represent both the synchronization existing among cortical areas that are entangled in tonic painful stimulus processing [52-54] and the activity of certain neural assemblies in a large web of neural networks [55-56]. Moreover, other studies reported an increase in gamma band activity in response to both painful electrical and painful laser stimuli [32, 57-60].

Therefore, it has been hypothesized that gamma oscillations would play a crucial role in cortical integration, as well as in pain perception and processing [29-34].

On the other hand, recent research has reported that gamma band power responses are triggered because of the attentional modulation of pain processing [59]. In other words, paying attention to pain leads to an increase in gamma band power [61]. Thus the findings of the current study can be due to a greater attention paid to the painful processes during the SETT and induced tonic pain. This demonstrates that during the experiment, the participants were aware of the painful processes.

Moreover, this study has shown that the gamma total power has decreased after the application of TENS. Yet, as we found no other studies investigating this issue, we are not able to compare our findings, accordingly. However, some studies demonstrated that gamma band oscillations could selectively encode the subjective perception of tonic pain [62]. The magnitude of these oscillations has been reported to decrease during hypnotic analgesia and transcranial direct current stimulation (tDCS) [63]. This finding suggests that certain non-pharmacological treatment, such as hypnosis, might exert analgesic effects by decreasing attentional processes or interrupting within-brain integration. This may lead to a sort of dissociation among brain systems or structures which are essential for the experience of pain [63]. Given this, the reduction of gamma total power after applying TENS (as a non- pharmacological treatment) in this study 
might be due to the analgesic effects of TENS.

\section{Alteration of Pain Intensity}

The findings of this study demonstrated that SETT gives a rise to tonic pain whose intensity is reduced remarkably ( $32.87 \mathrm{~mm}$ on VAS) after the application of TENS. In clinical settings, a reduction of $20 \mathrm{~mm}$ on VAS is considered meaningful [64-65].

This finding is consistent with those of some other studies that have shown a link between the application of high frequency TENS and the reduction of induced ischemic pain in healthy volunteers $[3,43]$. These studies have suggested that using high frequency TENS boosts impulse rates which, in turn, convey a stronger input to central nervous system. This will restrain the nociceptive transmission of second-order neurons to the brain based on the gate control theory of pain.

Moreover, studies carried out on animals exhibited that high-frequency TENS acted on delta $(\delta)$-opioid receptors, increasing the extracellular gamma-aminobutyric acid (GABA) concentration as well as reducing the glutamate and aspartate concentrations in the dorsal horn of the spinal cord [66-67]. Another study performed on human demonstrated that high dose naloxone could block the analgesic effects high-frequency TENS. This indicated that the analgesic effects of this kind of TENS involved endogenous opioids [68].

In addition to these findings, De Santana and Sluka [69] have exhibited the role of periaqueductal gray (PAG) in TENS induced analgesia. They hold that this is most probably because of the projections which were sent by the ventrolateral PAG to the spinal cord via rostroventral medulla (RVM) [70].

In this study, the pain was induced in healthy subjects who had no pain history. Therefore, the results might have been different in the subjects who have had real pain. It is recommended that future studies address the patients who have real pain. Moreover, since pain can alter all brain waves, it is suggested that the future studies evaluate the effect of TENS as an analgesic modality on other brain waves.

\section{Conclusion}

To the best of our knowledge, this is the first study is conducted to investigate the effect of high frequency TENS on the gamma band activity. The results of this study demonstrated that the high frequency TENS could reduce the enhanced gamma band activity after inducing tonic pain in healthy volunteers. This finding might help as a functional brain biomarker which could be used for pain treatment more specifically for EEG-based neurofeedback approaches.

\section{Acknowledgment}

Authors would like to express their thanks to all participants in this study. The present article was financially supported by Shiraz University of Medical Sciences, Deputy for Research Affairs (Grant No: 93-7272).

\section{Conflict of Interest}

We have no conflict of interest to report.

\section{References}

1. Electrophysiology APTASoC. Electrotherapeutic terminology in physical therapy: American Physical Therapy Association; 2000.

2. Moran F, Leonard T, Hawthorne S, Hughes CM, McCrum-Gardner E, Johnson MI, et al. Hypoalgesia in response to transcutaneous electrical nerve stimulation (TENS) depends on stimulation intensity. J Pain. 2011;12:929-35. doi.org/10.1016/j. jpain.2011.02.352. PubMed PMID: 21481649.

3. Johnson MI, Tabasam G. An investigation into the analgesic effects of interferential currents and transcutaneous electrical nerve stimulation on experimentally induced ischemic pain in otherwise pain-free volunteers. Phys Ther. 2003;83:208-23. PubMed PMID: 12620086.

4. Robb K, Oxberry SG, Bennett MI, Johnson MI, Simpson KH, Searle RD. A cochrane systematic review of transcutaneous electrical nerve stimulation for cancer pain. J Pain Symptom Manage. 2009;37:746-53. doi.org/10.1016/j.jpainsymman.2008.03.022. PubMed PMID: 18790600.

5. Kara M, Ozcakar L, Gokcay D, Ozcelik E, Yorubulut M, Guneri S, et al. Quantification of the effects of transcutaneous electrical nerve stimulation with functional magnetic resonance imaging: a dou- 
ble-blind randomized placebo-controlled study. Arch Phys Med Rehabil. 2010;91:1160-5. doi. org/10.1016/j.apmr.2010.04.023. PubMed PMID: 20684895.

6. Silva JG, Santana CG, Inocencio KR, Orsini M, Machado S, Bergmann A. Electrocortical Analysis of Patients with Intercostobrachial Pain Treated with TENS after Breast Cancer Surgery. J Phys Ther Sci. 2014;26:349-53. doi.org/10.1589/ jpts.26.349. PubMed PMID: 24707082. PubMed PMCID: 3976001.

7. Timofeeva MA, Ar'kov VV, Andreev RA, Trushkin EV, Tonevitsky AG. Changes in parameters of laser-induced potentials after transcutaneous electroneurostimulation. Bull Exp Biol Med. 2011;150:479-80. doi.org/10.1007/s10517-0111173-7. PubMed PMID: 22268048.

8. Johnson MI, Walsh DM. Pain: continued uncertainty of TENS' effectiveness for pain relief. Nat Rev Rheumatol. 2010;6:314-6. doi.org/10.1038/ nrrheum.2010.77. PubMed PMID: 20520646.

9. Hoshiyama M, Kakigi R. After-effect of transcutaneous electrical nerve stimulation (TENS) on painrelated evoked potentials and magnetic fields in normal subjects. Clin Neurophysiol. 2000;111:71724. doi.org/10.1016/S1388-2457(99)00299-0. PubMed PMID: 10727923.

10. Vassal F, Creac'h C, Convers P, Laurent B, GarciaLarrea L, Peyron R. Modulation of laser-evoked potentials and pain perception by transcutaneous electrical nerve stimulation (TENS): a placebocontrolled study in healthy volunteers. Clin Neurophysiol. 2013;124:1861-7. doi.org/10.1016/j. clinph.2013.04.001. PubMed PMID: 23639375.

11. de Tommaso $M$, Fiore $P$, Camporeale $A$, Guido $M$, Libro G, Losito $L$, et al. High and low frequency transcutaneous electrical nerve stimulation inhibits nociceptive responses induced by CO 2 laser stimulation in humans. Neuroscience letters. 2003;342:17-20. doi.org/10.1016/S03043940(03)00219-2.

12. Jensen MP, Hakimian S, Sherlin LH, Fregni F. New insights into neuromodulatory approaches for the treatment of pain. J Pain. 2008;9:193-9. doi. org/10.1016/j.jpain.2007.11.003. PubMed PMID: 18096437.

13. Kakigi R, Inui K, Tamura Y. Electrophysiological studies on human pain perception. Clin Neurophysiol. 2005;116:743-63. doi.org/10.1016/j. clinph.2004.11.016. PubMed PMID: 15792883.

14. Williams JD, Gruzelier JH. Differentiation of hypnosis and relaxation by analysis of narrow band theta and alpha frequencies. Int J Clin Exp Hypn. 2001;49:185-206. doi. org/10.1080/00207140108410070. PubMed PMID: 11430154.

15. Ma J, Wang S, Raubertas R, Svetnik V. Statistical methods to estimate treatment effects from multichannel electroencephalography (EEG) data in clinical trials. J Neurosci Methods. 2010;190:248-57. doi.org/10.1016/j.jneumeth.2010.05.013. PubMed PMID: 20580744.

16. Tinazzi M, Zarattini $S$, Valeriani $M$, Romito $S$, Farina S, Moretto G, et al. Long-lasting modulation of human motor cortex following prolonged transcutaneous electrical nerve stimulation (TENS) of forearm muscles: evidence of reciprocal inhibition and facilitation. Exp Brain Res. 2005;161:457-64. doi. org/10.1007/s00221-004-2091-y. PubMed PMID: 15551083.

17. Terman G, Bonica J. Spinal mechanisms and their modulation. Bonica's Management of Pain. 3rd ed. Baltimore, MD: Lippincott Williams \& Wilkins; 2001. p. 73-152.

18. Lorenz J, Garcia-Larrea L. Contribution of attentional and cognitive factors to laser evoked brain potentials. Neurophysiol Clin. 2003;33:293-301. doi.org/10.1016/j.neucli.2003.10.004. PubMed PMID: 14678843.

19. Chen AC. EEG/MEG brain mapping of human pain: recent advances. International Congress Series; 2002: Elsevier.

20. Chen AC. Human brain measures of clinical pain: a review. I. Topographic mappings. Pain. 1993;54:115-32. doi.org/10.1016/03043959(93)90200-9. PubMed PMID: 8233525.

21. Posner J. A modified submaximal effort tourniquet test for evaluation of analgesics in healthy volunteers. Pain. 1984;19:143-51. doi. org/10.1016/0304-3959(84)90834-0. PubMed PMID: 6462726.

22. Mima T, Oga T, Rothwell J, Satow T, Yamamoto $\mathrm{J}$, Toma K, et al. Short-term high-frequency transcutaneous electrical nerve stimulation decreases human motor cortex excitability. Neurosci Lett. 2004;355:85-8. doi.org/10.1016/j.neulet.2003.10.045. PubMed PMID: 14729241.

23. Bushnell M, Apkarian A. Representation of pain in the brain. Wall and Melzack's Textbook of Pain. 5th edition. London: Elsevier; 2006. p. 107-124.

24. Craig AD. Interoception: the sense of the physiological condition of the body. Curr Opin Neurobiol. 2003;13:500-5. doi.org/10.1016/S09594388(03)00090-4. PubMed PMID: 12965300.

25. Mouraux A, Guerit J-M, Plaghki L. Non-phase locked electroencephalogram (EEG) responses to CO2 laser skin stimulations may reflect central interactions between $\mathrm{A} \partial$-and $\mathrm{C}$-fibre afferent volleys. Clinical neurophysiology. 2003:114:710-22. doi. org/10.1016/S1388-2457(03)00027-0.

26. Ploner M, Gross J, Timmermann L, Pollok B, Schnitzler A. Pain suppresses spontaneous brain rhythms. Cereb Cortex. 2006;16:537-40. doi. org/10.1093/cercor/bhj001. PubMed PMID: 16033927.

27. Bromm B, Lorenz J. Neurophysiological evaluation of pain. Electroencephalogr Clin Neurophysiol. 1998:107:227-53. doi.org/10.1016/S00134694(98)00075-3. PubMed PMID: 9872441. 
28. Constant I, Sabourdin N. The EEG signal: a window on the cortical brain activity. Paediatr $A n$ aesth. 2012;22:539-52. doi.org/10.1111/j.14609592.2012.03883.x. PubMed PMID: 22594406.

29. Martinovic J, Busch NA. High frequency oscillations as a correlate of visual perception. Int $J$ Psychophysiol. 2011;79:32-8. doi.org/10.1016/j. ijpsycho.2010.07.004. PubMed PMID: 20654659.

30. Valentini E, Betti V, Hu L, Aglioti SM. Hypnotic modulation of pain perception and of brain activity triggered by nociceptive laser stimuli. Cortex. 2013;49:446-62. doi.org/10.1016/j.cortex.2012.02.005. PubMed PMID: 22464451.

31. Zhang ZG, Hu L, Hung YS, Mouraux A, Iannetti GD. Gamma-band oscillations in the primary somatosensory cortex--a direct and obligatory correlate of subjective pain intensity. $J$ Neurosci. 2012;32:7429-38. doi.org/10.1523/JNEUROSCI.5877-11.2012. PubMed PMID: 22649223.

32. Chen AC, Herrmann CS. Perception of pain coincides with the spatial expansion of electroencephalographic dynamics in human subjects. Neurosci Lett. 2001;297:183-6. doi.org/10.1016/S03043940(00)01696-7. PubMed PMID: 11137758.

33. Croft RJ, Williams JD, Haenschel C, Gruzelier $\mathrm{JH}$. Pain perception, hypnosis and $40 \mathrm{~Hz}$ oscillations. Int J Psychophysiol. 2002;46:101-8. doi. org/10.1016/S0167-8760(02)00118-6. PubMed PMID: 12433387.

34. Ohara S, Crone NE, Weiss N, Lenz FA. Analysis of synchrony demonstrates 'pain networks' defined by rapidly switching, task-specific, functional connectivity between pain-related cortical structures. Pain. 2006;123:244-53. doi.org/10.1016/j. pain.2006.02.012. PubMed PMID: 16563627.

35. Nir RR, Sinai A, Moont R, Harari E, Yarnitsky D. Tonic pain and continuous EEG: prediction of subjective pain perception by alpha-1 power during stimulation and at rest. Clin Neurophysiol. 2012;123:60512. doi.org/10.1016/j.clinph.2011.08.006. PubMed PMID: 21889398.

36. Bae YH, Lee SM. Analgesic effects of transcutaneous electrical nerve stimulation and interferential current on experimental ischemic pain models: frequencies of $50 \mathrm{hz}$ and $100 \mathrm{hz}$. J Phys Ther Sci. 2014;26:1945-8. doi.org/10.1589/jpts.26.1945. PubMed PMID: 25540504. PubMed PMCID: 4273064.

37. Marchand S, Li J, Charest J. Effects of caffeine on analgesia from transcutaneous electrical nerve stimulation. N Engl J Med. 1995;333:325-6. doi. org/10.1056/NEJM199508033330521. PubMed PMID: 7596392.

38. Hasan S. Comparative Study: Analgesic effect of Al-TENS in variation of treatment time on experimentally induced ischaemic pain in healthy young adult. Indian Journal of Physiotherapy and Occupational Therapy. 2013;7:250. doi.org/10.5958 /j.0973-5674.7.2.051.
39. Neal MJ, Murray BR. The analgesic effect of anaesthetic mixtures. The effect of nitrous oxide with trichlorethylene or halothane on experimental ischaemic pain. Guys Hosp Rep. 1966;115:19-26. PubMed PMID: 5904624.

40. Sacchetti G, Lampugnani R, Battistini C, Mandelli V. Response of pathological ischaemic muscle pain to analgesics. $\mathrm{Br} J$ Clin Pharmacol. 1980;9:165-9. doi.org/10.1111/j.1365-2125.1980. tb05828.x. PubMed PMID: 7356905. PubMed PMCID: 1429853.

41. Handwerker HO, Kobal G. Psychophysiology of experimentally induced pain. Physiol Rev. 1993;73:639-71. doi.org/10.1152/physrev.1993.73.3.639. PubMed PMID: 8332641.

42. Moore PA, Duncan GH, Scott DS, Gregg JM, Ghia JN. The submaximal effort tourniquet test: its use in evaluating experimental and chronic pain. Pain. 1979;6:375-82. doi.org/10.1016/03043959(79)90055-1. PubMed PMID: 460938.

43. Chen CC, Johnson MI. Differential frequency effects of strong nonpainful transcutaneous electrical nerve stimulation on experimentally induced ischemic pain in healthy human participants. Clin J Pain. 2011;27:434-41. doi.org/10.1097/ AJP.0b013e318208c926. PubMed PMID: 21415722.

44. Johnson MI, Tabasam G. A single-blind placebocontrolled investigation into the analgesic effects of interferential currents on experimentally induced ischaemic pain in healthy subjects. Clin Physiol Funct Imaging. 2002;22:187-96. doi. org/10.1046/j.1475-097X.2002.00416.x. PubMed PMID: 12076344.

45. Droste C, Greenlee MW. Two separate components of pain produced by the submaximal effort tourniquet technique. Pain. 1985;23:95-6. doi. org/10.1016/0304-3959(85)90234-9. PubMed PMID: 4058930.

46. Pertovaara A, Nurmikko T, Pontinen PJ. Two separate components of pain produced by the submaximal effort tourniquet test. Pain. 1984;20:53-8. doi.org/10.1016/0304-3959(84)90810-8. PubMed PMID: 6493789.

47. Reinert A, Treede R, Bromm B. The pain inhibiting pain effect: an electrophysiological study in humans. Brain Res. 2000;862:103-10. doi. org/10.1016/S0006-8993(00)02077-1. PubMed PMID: 10799674.

48. Guo-Sheng Y, Jiang W, Bin D, Xi-Le W, ChunXiao $\mathrm{H}$. Modulation of electroencephalograph activity by manual acupuncture stimulation in healthy subjects: An autoregressive spectral analysis. Chinese Physics B. 2013;22:028703. doi. org/10.1088/1674-1056/22/2/028703.

49. Chang PF, Arendt-Nielsen L, Graven-Nielsen $T$, Chen AC. Psychophysical and EEG responses to repeated experimental muscle pain in humans: pain intensity encodes EEG activity. Brain Res Bull. 2003;59:533-43. doi.org/10.1016/S0361- 
9230(02)00950-4. PubMed PMID: 12576151.

50. Bertrand 0, Tallon-Baudry C. Oscillatory gamma activity in humans: a possible role for object representation. Int J Psychophysiol. 2000;38:21123. doi.org/10.1016/S0167-8760(00)00166-5. PubMed PMID: 11102663.

51. Tallon-Baudry C, Bertrand 0. Oscillatory gamma activity in humans and its role in object representation. Trends Cogn Sci. 1999;3:151-62. doi. org/10.1016/S1364-6613(99)01299-1. PubMed PMID: 10322469.

52. Kaiser J, Hertrich I, Ackermann H, Lutzenberger W. Gamma-band activity over early sensory areas predicts detection of changes in audiovisual speech stimuli. Neuroimage. 2006;30:1376-82. doi. org/10.1016/j.neuroimage.2005.10.042. PubMed PMID: 16364660.

53. Kaiser J, Lutzenberger W. Induced gamma-band activity and human brain function. Neuroscientist. 2003;9:475-84. doi. org/10.1177/1073858403259137. PubMed PMID: 14678580.

54. Burgess AP, Ali L. Functional connectivity of gamma EEG activity is modulated at low frequency during conscious recollection. Int $J$ Psychophysiol. 2002;46:91-100. doi.org/10.1016/S01678760(02)00108-3. PubMed PMID: 12433386.

55. Shibata T, Shimoyama I, Ito T, Abla D, Iwasa $\mathrm{H}$, Koseki $\mathrm{K}$, et al. Attention changes the peak latency of the visual gamma-band oscillation of the EEG. Neuroreport. 1999;10:1167-70. doi. org/10.1097/00001756-199904260-00002. PubMed PMID: 10363918.

56. Sokolov A, Lutzenberger W, Pavlova M, Preissl $\mathrm{H}$, Braun C, Birbaumer N. Gamma-band MEG activity to coherent motion depends on task-driven attention. Neuroreport. 1999;10:1997-2000. doi.org/10.1097/00001756-199907130-00001. PubMed PMID: 10424663.

57. De Pascalis V, Cacace I, Massicolle F. Perception and modulation of pain in waking and hypnosis: functional significance of phase-ordered gamma oscillations. Pain. 2004;112:27-36. doi. org/10.1016/j.pain.2004.07.003. PubMed PMID: 15494182.

58. De Pascalis V, Cacace I. Pain perception, obstructive imagery and phase-ordered gamma oscillations. Int J Psychophysiol. 2005;56:157-69. doi. org/10.1016/j.jpsycho.2004.11.004. PubMed PMID: 15804450.

59. Hauck M, Lorenz J, Engel AK. Attention to painful stimulation enhances gamma-band activity and synchronization in human sensorimotor cortex. $J$ Neurosci. 2007;27:9270-7. doi.org/10.1523/JNEUROSCI.2283-07.2007. PubMed PMID: 17728441.

60. Gross J, Schnitzler A, Timmermann L, Ploner M. Gamma oscillations in human primary somatosensory cortex reflect pain perception. PLOS Biol. 2007;5:e133. doi.org/10.1371/journal. pbio.0050133. PubMed PMID: 17456008. PubMed PMCID: 1854914.

61. Hauck M, Domnick C, Lorenz J, Gerloff C, Engel AK. Top-down and bottom-up modulation of pain-induced oscillations. Front Hum Neurosci. 2015:9:375. doi.org/10.3389/fnhum.2015.00375. PubMed PMID: 26190991. PubMed PMCID: 4488623.

62. Schulz E, May ES, Postorino M, Tiemann L, Nickel MM, Witkovsky V, et al. Prefrontal Gamma Oscillations Encode Tonic Pain in Humans. Cereb Cortex. 2015;25:4407-14. doi.org/10.1093/cercor/ bhv043. PubMed PMID: 25754338. PubMed PMCID: 4816790.

63. Jensen MP, Sherlin LH, Askew RL, Fregni F, Witkop $G$, Gianas A, et al. Effects of non-pharmacological pain treatments on brain states. Clin Neurophysiol. 2013;124:2016-24. doi.org/10.1016/j. clinph.2013.04.009. PubMed PMID: 23706958. PubMed PMCID: 3759647.

64. Farrar JT, Young JP, Jr., LaMoreaux L, Werth $\mathrm{JL}$, Poole RM. Clinical importance of changes in chronic pain intensity measured on an 11-point numerical pain rating scale. Pain. 2001;94:14958. doi.org/10.1016/S0304-3959(01)00349-9. PubMed PMID: 11690728.

65. Dworkin RH, Turk DC, Wyrwich KW, Beaton D, Cleeland CS, Farrar JT, et al. Interpreting the clinical importance of treatment outcomes in chronic pain clinical trials: IMMPACT recommendations. J Pain. 2008;9:105-21. doi.org/10.1016/j. jpain.2007.09.005. PubMed PMID: 18055266.

66. Maeda Y, Lisi TL, Vance CG, Sluka KA. Release of GABA and activation of GABA(A) in the spinal cord mediates the effects of TENS in rats. Brain Res. 2007;1136:43-50. doi.org/10.1016/j. brainres.2006.11.061. PubMed PMID: 17234163. PubMed PMCID: 2746639.

67. Sluka KA, Vance CG, Lisi TL. High-frequency, but not low-frequency, transcutaneous electrical nerve stimulation reduces aspartate and glutamate release in the spinal cord dorsal horn. J Neurochem. 2005;95:1794-801. doi.org/10.1111/j.14714159.2005.03511.x. PubMed PMID: 16236028.

68. Leonard G, Goffaux P, Marchand S. Deciphering the role of endogenous opioids in high-frequency TENS using low and high doses of naloxone. Pain. 2010;151:215-9. doi.org/10.1016/j. pain.2010.07.012. PubMed PMID: 20728275.

69. DeSantana J, Sluka K, editors. Antinociceptive effect of transcutaneous electric nerve stimulation (TENS) is mediated by ventrolateral periaqueductal grey (VIPAG). XII World Congress in Pain; 2008.

70. DeSantana JM, Walsh DM, Vance C, Rakel BA, Sluka KA. Effectiveness of transcutaneous electrical nerve stimulation for treatment of hyperalgesia and pain. Curr Rheumatol Rep. 2008;10:492-9. doi. org/10.1007/s11926-008-0080-z. PubMed PMID: 19007541. PubMed PMCID: 2746624. 